\title{
Um (in) feliz ano: a retomada após a Segunda Guerra Mundial
}

\section{Not satisfied year: the resumption after World War II}

\author{
Rodrigo dos Santos*
}

BURUMA, IAN. Ano Zero: Uma história de 1945. São Paulo: Companhia das Letras, 2015.

\begin{abstract}
A história de meu pai [...] não tão ruim quanto tantas outras, mas assim mesmo bem ruim - foi o que me deixou curioso sobre o que aconteceu logo após a guerra mais devastadora da história humana (p. 20).

Meu próprio interesse no período imediato do pós-guerra foi despertado em parte pelos acontecimentos atuais. [...] eu queria recuar no tempo para entender o mundo de meu pai e sua geração [...] curiosidade que cresce ainda mais quando o filho fica mais velho do que era o pai naquela época (p.22).
\end{abstract}

A motivação do historiador Ian Buruma para a escrita da obra Ano Zero está nestes trechos. Ele pretende responder as perguntas do presente, retornando ao passado. Sua motivação encontra-se na participação de seu pai no ano de 1945, em que se teve um continente Europeu destruído pela Segunda Grande Guerra. Fato que mobilizou todos os países deste planeta.

$\mathrm{O}$ autor conta a história de seu pai durante a Segunda Guerra e como ela está relacionada à sua pesquisa: "Eu era muito jovem quando ouvi meu pai falar da guerra pela primeira vez. Ao contrário de algumas pessoas, ele não era reticente quanto a isso, ainda que algumas memórias devessem ser dolorosas quando evocadas. Eu gostava de ouvi-las [...]” (p. 11).

(c) EY Direito autoral e licença de uso: Este artigo está licenciado sob uma Licença Creative Commons. Com essa licença você pode compartilhar, adaptar, para qualquer fim, desde que atribua a autoria da obra, forneça um link para a licença, e indicar se foram feitas alterações. 
Buruma conta que seu pai nasceu em Nijmegen no leste da Holanda, cursando direito na Universidade de Utrecht em 1941: "A vida continuou, mesmo sob ocupação. Para a maioria do povo holandês, contanto que não fossem judeu, tudo continuou estranhamente normal [...] Meu pai entrou na Universidade de Utrecht em 1941, onde estudou direito [...]" (p.13).

Entretanto, em 1943, os jovens estudantes de direito foram coagidos a uma ação:

No início de 1943, os jovens foram submetidos a outro teste, bem mais sério. As forças de ocupação alemãs ordenaram que todos os estudantes assinassem um voto de lealdade, jurando eximir-se de qualquer ação contra o Terceiro Reich. Os que se recusassem seriam deportados para a Alemanha e obrigados a trabalhar para a indústria bélica nazista. Assim como $85 \%$ de seus colegas, meu pai recusou-se e passou a viver escondido (p. 14).

No mesmo ano, seu pai foi capturado pelos nazistas, depois de um chamado da resistência estudantil de Utrecht:

Infelizmente, os nazistas tinham escolhido aquele mesmo momento para arrebanhar jovens que iriam trabalhar na Alemanha [...] Ele foi transportado [...] para um pequeno e horroroso campo de concentração [...] Após um breve período ali, meu pai passou o resto da guerra trabalhando numa fábrica em Berlim, produzindo freios para composições ferroviárias (p.14;15).

Em 1945, a partir de contatos, ele conseguiu abrigo em uma casa que escondia refugiados. No mesmo ano quase foi fuzilado: “[...] Mas meu pai quase perdeu a vida quando o revólver do dr Rümmelin foi descoberto. [...] Mas então, [...] apareceu um oficial russo que falava inglês. Ele resolveu acreditar na história do dr Rümmelin. O fuzilamento foi cancelado" (p. 17). Com o fim da guerra, depois de desfalecer-se chegou a um campo de acolhimento ${ }^{1}$, voltando a sua casa em setembro de 1945 .

Depois de conhecer a motivação do pesquisador é necessário apresentálo e seu local de produção ${ }^{2}$. De origem holandesa, Ian Buruma nasceu em Haia em 1951, sendo educado na Holanda e no Japão. Já realizou palestras em instituições como a Universidade de Oxford, Princeton e Harvard. Na atualidade é professor no Bard College em Nova York ${ }^{3}$. O referido autor escreve no mesmo estilo dos pesquisadores Ben Shephard ${ }^{4}$ e Tony Judt ${ }^{5}$. Estes pesquisadores também fazem parte de sua bibliografia.

Entretanto, o que diferencia Ian Buruma destes demais pesquisadores? A primeira resposta pode ser concentrar-se no desenrolar de um ano, o fim 
da guerra e suas consequências mais imediatas. O segundo ponto, e mais relevante, é considerar a mundialidade do conflito. O autor aponta como se desenrolou conflitos locais como a tentativa de independência da Argélia, bem como ocorreu o fim da guerra e início da "paz" nas Filipinas, Índia, China, Indonésia e Japão. Além de considerar o continente europeu, com destaque para a Holanda.

Ele menciona que os líderes japoneses não foram punidos pelos Aliados da mesma forma que os líderes nazistas, o imperador japonês foi considerado uma "vítima" da situação e não um organizador do conflito. Além disso, a punição não foi executada da mesma forma no leste como no oeste da Europa, ou em cada país envolvido no confronto. O julgamento de execução de sentenças pelos Aliados levou em considerações interesses.

Um de seus pontos fracos encontra-se em representar os deslocados ou refugiados de guerra. Ele não comenta sobre a organização destes campos de acolhimento e o papel das instituições internacionais. A UNRRA (United Nations Relief and Rehabilitation Administration) é citada brevemente, com um pronunciamento do Primeiro Ministro do Reino Unido: Winston Churchill. Este esquecimento pode ter sido proposital, se considerou satisfatoriamente a análise empreendida por Bem Shephard ${ }^{6}$ que dedicou uma obra a estes sujeitos.

Outras obras recentes, já traduzidas em português, que se concentram neste período são os livros de Anne Applebaum ${ }^{7}$ e Keith Lowe ${ }^{8}$. Diante disso, Ian Buruma utiliza de uma gama variada de fontes que compreende jornais e revistas do período, pronunciamento de funcionários, imagens, diários, mapas, músicas e filmes. Igualmente merece destaque em suas fontes a utilização de escritos de Simone de Beauvoir sobre o período e sobre o pensamento de Jean- Paul Sartre quando este visita os Estados Unidos?.

Além de seu prólogo, a edição brasileira que possui a tradução de Paulo Geiger ${ }^{10}$ conta com três partes de desenvolvimento (Parte I- Complexo de Libertação, Parte II - Removendo o entulho, Parte III Nunca mais), cada uma com três capítulos; epílogo; agradecimento; notas; crédito das imagens; e índice remissivo. Na epígrafe se possui a alusão de Walter Benjamin ao quadro Angelus Novus de Paul Klee ${ }^{11}$, e no meio da obra imagens do ano de 1945 na Europa.

A primeira parte da obra divide-se nos três primeiros capítulos: 1 . Regozijo, 2. Fome, 3. Vingança. O primeiro capítulo apresenta que não necessariamente os "libertados" estavam felizes com a chegada dos Aliados. Enquanto se se esperava um agradecimento pelos ex-prisioneiros dos campos, alguns receberam com rispidez. Esse capítulo foca no imediato à libertação de áreas ocupadas pelo Eixo.

Apesar disso, em outros lugares ocorreram comemorações: "Em Nova York, 500 mil pessoas comemoravam nas ruas [...]” (p. 35). Em outros, não 
significou quase nada: “[...] O Dia da Vitória em Paris foi considerado por alguns como uma espécie de anticlímax. A França, afinal, já tinha sido libertada em 1944 [...]" (p. 36) ou "Minha avó, na Inglaterra, ansiando pela volta do marido, que ainda servia no Exército inglês na Índia, não podia compartilhar da animação dos filhos [...]”' (p. 37).

Ainda neste capítulo se destaca os elementos: a ausência da figura masculina no pós-guerra, especialmente na Holanda, Bélgica, França, Alemanha e Japão pelas baixas da guerra; As altas taxas de DST (doenças sexualmente transmissíveis) e natalidade, advinda principalmente da necessidade de reprodução nos campos de acolhimento; as Panpan e as Ruinemäuschen (damas de companhia de soldados aliados, as primeiras no Japão e as outras na Alemanha).

O segundo capítulo apresenta a fome como protagonista: "Havia fome em quase todas as partes do mundo, nos países libertados e nos derrotados também, onde todos os serviços tinham entrado em colapso, e os dispositivos econômicos normais tinham parado de funcionar" (p. 80). A fome encontravase, em seu pior caso, nos campos de concentração abandonados em retirada.

Os aliados não sabiam como trabalhar com essa situação, dando muitas vezes as mesmas rações que tinham para seus soldados; os organismos que não estavam acostumados acabavam morrendo por não conseguir digerir estes alimentos: "[...] Tudo que poderiam oferecer àqueles famintos eram suas próprias rações do Exército [...] Intestinos humanos atrofiados não são capazes de assimilar essa comida [...] Cerca de 2 mil delas morreram em consequência disso" (p. 82)

Outro ponto que o capítulo também destaca é como Grã-Bretanha sobreviveu a fome, a destruição de cidades alemães, italianas e francesas no fim da guerra, e o drama dos deslocados de guerra:

O grau de miséria humana que resultou era tão grande, e tão disseminado que as comparações são quase inúteis. A Alemanha tinha que lidar não apenas com seus próprios cidadãos e soldados que voltavam, mas também com mais de 10 milhões de refugiados falantes de alemão [...] Isso acrescentou um número enorme de pessoas às massas que se deslocavam em busca de alimento e abrigo (p. 91).

O terceiro capítulo foca na vingança, merecendo destaque para a participação feminina: "A colaboração feminina com o inimigo era principalmente no terreno sexual [...] Pessoas que haviam solapado a moral nacional com seu comportamento impatriótico, tal como o de dormir com as forças de ocupação [...]" (p. 117). Dormir com o "inimigo" poderia render “[...] desfilar, despidas, as cabeças raspadas, com suásticas pintadas em várias partes de sua anatomia. [...] escarnecidas, cuspidas e achacadas de outras maneiras. 
[...] encerradas em jaulas improvisadas e estupradas por seus carcereiros. Mais de 2 mil foram mortas" (p. 117).

$\mathrm{O}$ estupro era considerado uma vingança às mulheres que tinham dormido com soldados inimigos. Muitas possuíam seu cabelo raspado por vingança e utilizavam lenços ou chapéus, frequentando bordeis e dormindo com soldados aliados. Conseguir alimentação ou trocar cigarros dos aliados no mercado negro foi condição de sobrevivência. No Japão foi criado bordeis específicos para aliados, na tentativa de conter estupros.

Com relação aos judeus, mesmo após a guerra muitos foram mortos, especialmente pelos governos ditos comunistas; restando o sonho Palestino: "Mais de mil judeus foram assassinados na Polônia entre os verões de 1945 e 1946" (p. 121). Além do deslocamento forçado de populações inteiras de judeus e não judeus pela Europa, conflitos entre etnias, ou ainda, as repatriações forçadas.

A segunda parte da obra apresenta os capítulos: 4. A caminho de casa, 5. Drenando o veneno, 6; O império da lei.

O quarto capítulo apresenta com maior afinco o retorno dos deslocados de guerra:

\begin{abstract}
Meu pai foi um dos mais de 8 milhões de 'deslocados de guerra retidos na Alemanha em maio de 1945 [...] Havia cerca de 3 milhões mais em outras partes da Europa, alguns sentindo saudade de casa, alguns querendo ir para qualquer lugar, menos e voltar, e outros que não tinham mais uma casa para onde retornar (p. 175)
\end{abstract}

O autor afirma de que mais de 11 milhões de pessoas estavam fora de sua casa, pela dinâmica da Segunda Guerra Mundial. Além disso, ele adverte que todas as guerras deslocaram pessoas como exemplo cita a Guerra do Iraque de 2003 que retirou 5 milhões de pessoas de sua origem.

Alguns deslocados voltaram para casa e ainda a encontraram lá, outros tiveram suas casas ocupadas por outras famílias; outros ainda, não encontraram seus familiares: haviam morrido durante a guerra. $\mathrm{O}$ retorno foi um processo traumático, especialmente dos removidos à força: "[...] O que eles não esperavam eram que os britânicos, tidos como o povo mais cavalheiresco, decente e generoso da Europa, iriam forçá-los a seguir esse caminho" (p. 194).

As cenas de repatriação forçada:

[...] Quando o engodo não era suficiente para aplacar as pessoas e leva-las a concordas, soldados britânicos endurecidos pelo combate, às vezes em lágrimas, tinham de força-las a subir em vagões e caminhões de gado, empurrando, batendo, em certos momento usando baionetas. 
Mulheres aos prantos jogavam-se a seus pés, crianças eram esmagadas pela multidão aterrorizada, algumas pessoas foram atingidas por tidos, e outras preferiram, em vez da deportação, apunhalar-se no pescoço ou se atirar no rio Drau (p. 201).

Outras formas de limpeza étnica também foram promovidas em 1945:

A limpeza étnica de 1945, no entanto, foi além de deportar ou escravizar pessoas. [...] O que estava sendo destruído sistematicamente em 1945 era a cultura alemã, junto com muita gente que a tinha vivenciado. [...] Letreiros e sinalizações de ruas e de lojas foram repintados; nomes de logradouros, alterados; bibliotecas alemães, saqueadas; monumentos, demolidos; inscrições [...], apagadas em igrejas e outros edifícios públicos; a própria língua alemã teria de ser abolida (p. 210).

O quinto capítulo é que abriga as imagens da obra. O capítulo ainda problematiza a culpabilização da guerra. Quem deveria ser culpado? Quais sujeitos? Quais sujeitos deveriam ser julgado e condenado ao expurgo? Banimento, fuzilamento ou reincorporação? Como julgar sujeitos que poderiam reconstruir essas sociedades? Quem e como deveria ser governado os países no pós-guerra? "Além de provocar destruição física nos países envolvidos, a guerra, a ocupação ou a ditadura os corrompem também moralmente. A legitimidade política se perde. O sentimento cívico é corroído pelo cinismo [...]" (p.240).

Como tentativa de responder a estas perguntas Buruma aponta que em alguns foram usados bodes expiatórios, apenas para acabar a população que ansiava por justiça e quem sabe outros que colaboraram mais com os nazistas deveriam ser condenados. No Japão a polícia Kempeitai foi expurgada: "Cerca de 40 funcionários da Kempeitai perderam seus empregos; poucas lágrimas japonesas foram derramadas por eles [...]” (p. 242).

Em outros casos, os tribunais populares já tinham resolvido à situação: "Nessa ocasião, no entanto, grande parte da justiça com as próprias mãos já estava feita. Prisioneiros tinham sido linchados, mais de 4 mil pessoas foram sumariamente executadas, algumas delas enforcadas por multidões frenéticas [...]" (p. 260).

O sexto capítulo, dá seguimento aos julgamentos dos colaboracionistas: "[...] A justiça era sumária, e os rituais legais, rudimentares, quando não primitivos" (p. 265). "O primeiro julgamento por crimes de guerra no Pacífico foi o do general Tomoyuki Yamashita [...]" (p. 276). "Em seu julgamento, no outono de 1945, Yamashita foi acusado de ter permitido uma das piores 
atrocidades cometidas durante a Segunda Guerra Mundial: O Massacre de Manila" (p. 277).

O Julgamento não foi justo como Ian Buruma apresenta: “Certamente Yamashita não teve um julgamento justo. Os juízes eram oficiais da burocracia militar cujo conhecimento das leis era tão pobre quanto seu entendimento das condições num campo de batalha" (p. 280). Além disso, "Não houve tempo para examinar as mais de sessenta acusações, e outras ainda foram acrescentadas logo antes de o julgamento começar" (p. 280). Mais uma vez o autor ressalta que "a punição dos culpados tem de se equilibrar com outros interesses" (p. 306).

A última parte "Nunca mais" de alguma forma aponta os caminhos que foram tomados para que não ocorressem estes traumas novamente (capítulos: 7 . Um luminoso e confiante alvorecer, 8. Civilizando os Brutos, 9. Um mundo só).

No sétimo capítulo: "Nunca mais' era um sentimento que todas as pessoas tinham sofrido no pior conflito humano da história poderiam compartilhar" (p. 312). Na libertação de um campo de concentração pelos aliados em Buchenwald esse leva também foi descrito. Era a esperança para um futuro que não se sabia como proceder.

Neste capítulo, também se apresenta a chegada dos Soviéticos em territórios desocupados como exemplo a Coreia: "No início, houve alguns mal-entendidos. Pesou-se que os soviéticos estavam chegando, e foram enviados comitivas de boas-vindas à estação ferroviária de Seul para saudar os libertadores russos, que nunca vieram" (p. 339). Estava dada a largada para o que posteriormente chamou-se guerra fria.

O oitavo capítulo refere-se a como deveriam ser tratados os "perdedores" da guerra, os inimigo. A tradução brasileira do nome do capítulo é próxima à edição do livro de Shephard ${ }^{12}$. Ian Buruma possui a tradução de "Civilizando os brutos", enquanto Shephard "Alimentar os brutos?". Uma tentativa de desnazificar especialmente a Alemanha é o desafio apontado nestas páginas: "No início, de fato, houve planos, elaborados, em sua maioria, em Washington, para punir os ex-inimigos e torna-los inofensivos ao destruir todos os meios pelos quais pudessem se tornar nações industriais modernas" (p. 354). De alguma forma isto poderia não conter o avanço dos comunistas, com isso: "esses esquemas não foram adiante e acabaram substituídos pelos três Ds: Desmilitarização, Desnazificação, Democratização [...]” (p. 354). Um dos caminhos foi pela (re) educação, com o controle de escolar na substituição de heróis do regime nazista, a exibição forçada de filmes e a vinda de filmes de hollywood. Os filmes deveriam mostrar aspectos grandiosos dos aliados e não se remeter a episódios considerados tristes. Os Estados Unidos deveria ser o modelo.

O nono capítulo aponta o papel da Organização das Nações Unidas e sua constituição com o principal objetivo da paz. Além disso, destaca o fim 
do que o Buruma chamou de Ano Zero, o ano do início, do recomeço: "E assim o Ano Zero finalmente terminava, num misto de gratidão e ansiedade. Agradecidas por ter sido alcançado algum tipo de paz na maioria dos lugares [...]" (p. 423).

Com relação ao epílogo, o autor aponta que o fim da guerra pode apenas ter ocorrido em 1989, além de um novo reencontro de Ian Buruma e seu pai com a Berlim de 1989.

A riqueza da obra Ano Zero está na sua abordagem, na fluidez da escrita de Ian Buruma e na sua gama de fontes. Percebe-se que é um trabalho que possuí fôlego, apontando relações entre o oriente e o oeste. Preenchendo lacunas presentes na narrativa histórica que representa o que ocorreu após a Segunda Guerra Mundial, no advento da Guerra Fria.

\section{Notas}

* Professor Substituto da Universidade Federal da Fronteira Sul- UFFS/Laranjeiras do Sul/ Paraná, Brasil. E-mail: digao_santos9@hotmail.com

$1 \mathrm{O}$ pesquisador utiliza o termo campo de deslocados, entretanto nestes campos existiam deslocados, refugiados e os colaboracionistas. Por isso, se opta pela designação de campos de acolhimentos (SANTOS, Rodrigo dos. Discursos sobre imigração no jornal Folha do Oeste- Guarapuava, Paraná (1946-1960). 2015. 113f. Dissertação (Mestrado em História)Universidade Estadual do Centro-Oeste, Irati.).

2 Segundo Certeau na análise histórica deve se pensar o lugar social dos sujeitos, sendo construídos também em função de uma instituição. Além disso, deve-se pensar a historicidade e as escolhas que envolvem os pesquisadores. (CERTEAU, Michel de. A Operação Historiográfica. In: . A Escrita da História. Rio de Janeiro: Forense-Universitária, 1982).

3 Disponível no site pessoal do pesquisador: https://ianburuma.com/

4 SHEPHARD, Ben. A longa estrada para casa: restabelecendo o cotidiano na Europa devastada pela guerra. São Paulo: Paz e Terra, 2012.

5 JUDT, Tony. Pós Guerra: uma história da Europa desde 1945. Rio de Janeiro: Objetiva, 2008.

6 SHEPHARD. Op. Cit.

7APPLEBAUM, Anne. Cortina de Ferro: o esfacelamento do Leste Europeu (1944-1956). São Paulo: Três Estrelas, 2016.

8 LOWE, Keith. Continente selvagem: o caos na Europa depois da Segunda Guerra Mundial. Rio de Janeiro: Zahar, 2017.

9 Uma biografia de Sobre Beauvoir e Sartre pode ser encontrada em: SEYMOUR-JONES, Carole. Uma Relação Perigosa [Simone de Beauvoir e Jean Paul Sartre]. Rio de Janeiro: Record Editora, 2014.

10 Sobre Paulo Geiger https://www.companhiadasletras.com.br/autor.php?codigo $=02586$ 
11 BENJAMIN, Walter. Sobre o conceito de História. In: Magia e Técnica, arte e política: ensaios sobre literatura e história da cultura. São Paulo: Brasiliense, 1996.

12 SHEPHARD. Op. Cit.

Recebido em: 22/08/2017

Aprovado em: 19/11/2017 